\title{
Visão artificial
}

\author{
Harley E. A. Bicas, Marcos P. Ávila
}

Da visão decorre a quase totalidade do conhecimento que o homem constrói sobre o ambiente em que vive. Entretanto, uma reflexão sobre como esse processo de representação da natureza mostra-se limitado e sobre como tal domínio pode ser estendido, dimensiona a fragilidade humana e a grandeza em sua possível superação. De fato, as impressionantes capacidades para discriminar a luz em suas cores e matizes, em suas intensidades e contrastes; a percepção das formas e movimentos de suas fontes, representam, apenas, a resolução de uma estreitíssima faixa dos múltiplos comprimentos de onda com que se manifestam as diferentes formas de energia radiante. O homem é cego aos raios cósmicos, aos raios gama e $\mathrm{X}$, às radiações ultravioleta e infravermelha, às ondas hertzianas do rádio e da televisão. Mas daí a meditação sobre sua grandeza: cego, mas capaz de captar todas essas energias e transformálas a seu proveito. Cego, mas orgulhoso de seu engenho. O Homem pode olhar, inclusive, para dentro de seu próprio corpo. Pode ver a distâncias até há pouco tempo inimagináveis: o jogo de futebol do outro lado do mundo, o pedregulho no solo de Marte. Tanto pode ver que conseguiu ainda fazê-lo vencendo o tempo, perenizando imagens em fotos, filmes e arquivos eletrônicos.

Ora, diante de tanta visão artificial já disponível, cantandose todas as vitórias do homem sobre o tempo e o espaço e a multiplicação de seu poder sobre o Universo, restaria agora usar essa tecnologia para fazer ver a um cego (cego propriamente dito, não simplesmente o cego vidente que somos nós). Mas, para isso, afastem-se as alternativas ou truques de uma visão substitutiva paralela como a originada da captação do contorno de um objeto com uma microcâmera, transmitido a um painel e nele reproduzido em forma de vibrações, perceptíveis pelo tato, apenas uma forma sofisticada de leitura Braille, há muito conhecida: não serve. Não serve ainda usar recursos que aumentem o tamanho de imagens, como os aplicados para melhorar a chamada visão subnormal: pressupõe a existência de visão, assim melhor aproveitada.

Busca-se um método que faça renascer capacitações naturais, como o do transplante de células retínicas fotorreceptoras. Busca-se uma forma de substituí-las por dispositivos fotossensíveis (próteses), que transmitam sinais equivalentes aos das células retínicas, sejam eles de captação direta do estímulo luminoso (próteses sub-retinianas) ou de sua transmissão indireta após captação por fotossensores externos (as próteses de nervo óptico, epirretínicas e as corticais). As perspectivas de desenvolvimento dessas técnicas são reais e já foram apresentados experimentos que as comprovam. Por outro lado, resta saber que contradições e dificuldades se abrem a partir de tais conquistas. Afinal, contrapontos sempre foram substantivos à ciência, modulando-lhe os avanços, apontando-lhe cautela, sugerindo alternativas.

De fato, estes caminhos substitutivos atualmente abertos ainda se apresentam eivados de problemas. No caso da prótese epirretínica (na superfície da retina) ou sub-retínica (junto ao epitélio pigmentar, mais próxima das células receptoras) pergunta-se se o estímulo deva ser "direto", da própria imagem, formada sobre componentes do artefato que (como os fotorreceptores) gerariam um sinal, ou repassado aos elementos visuais por sinais elétricos, previamente desencadeados por uma microcâmera (de recepção de imagens). Trata-se, na verdade, de questão mais técnica do que conceitual. Tanto na hipótese do estímulo pela imagem (que gera uma resposta da prótese) quanto na do estímulo por um sinal elétrico já codificado, pressupõe-se a integridade de parte dos elementos retínicos receptores (os fotorreceptores) para subordinar a mensagem a neurônios do corpo geniculado lateral. Daí surge a grande limitação desse processo: a maior parte das cegueiras se deve a perdas de elementos retínicos transmissores (células ganglionares), ou de seus axônios (constituintes do nervo óptico), condição que inviabiliza a transmissão retinocortical. Por outro lado, a substituição satisfatória desse sistema de captação e sinalização exigiria um mosaico de elementos fotorreceptores semelhante ao da retina normal, uma estrutura delicadíssima (dependente de campos receptivos centrais ligados a cones com diâmetros de 1,5 a $2 \mu \mathrm{m}$ ), calculando-se a densidade topográfica dos elementos em cerca de 150 a $200 \mathrm{mil} / \mathrm{mm}^{2}$ (ou mais). Mas não bastasse tal precisão arquitetônica, de difícil execução mesmo com microtecnologias, convém lembrar a necessidade de se reproduzir as interações funcionais entre os campos receptivos, garantidas pelas múltiplas ligações das células bipolares e ganglionares com as fotorreceptoras e pelas modulações entre elas, dadas por células horizontais e amácrinas, daí resultando um complexo espectro de respostas. Realmente, sinais neurais tanto são suscitados pelo estímulo luminoso, em campos receptivos on, como por sua cessação, nos campos receptivos off, ou ainda produzidos pelo início e fim do estímulo (campos receptivos on-off), mas não enquanto ele se mantém! Mais: a resposta retínica ao estímulo luminoso é relativística e não um registro simples e linear do nível absoluto da iluminação incidente. Assim, uma área A suscita sensação de "claridade" ou de "obscuridade" não em função 
da iluminação incidente (como a resposta de uma célula fotoelétrica) mas na dependência de como as áreas circunjacentes são estimuladas. Ou seja, A reage com a sensação de "claro" e $B$ de "escuro" em função de suas respectivas vizinhanças A' e $\mathrm{B}^{\prime}$ serem estimuladas em menos e mais luz, ainda que A (sensação de "claro") receba menos luz do que B (sensação de "escuro"). Nem mesmo é obedecida a simples regra de que a freqüência dos potenciais de ação desencadeados como sinal neural representa o código básico pelo qual é interpretada a intensidade do estímulo luminoso: no fenômeno de adaptação (efeito Troxler), a freqüência da resposta diminui (inicialmente) apesar da invariabilidade da iluminação incidente sobre a retina.

Certamente, daí, a razão dos fenômenos de inibição lateral, da somação temporal (com a lei de Bloch), da somação espacial (com a lei de Ricco), das interpretações subjetivas de variações de textura e contrastes, difíceis de traduzir. Também não se chegou, ainda, a uma compreensão terminal sobre como as cores são distingüidas em suas combinações, matizes e nuanças, para que um modelo que reproduza essas percepções venha a ser concebido.

Por fim (embora sem esgotar o assunto), são relevantes as considerações sobre os riscos inerentes à implantação da prótese, como os descolamentos e lesões de retina, inflamações, infecções, recrudescimento de afecções latentes. É preciso estar atento à sua biocampatibilidade e à eventual nocividade de seus processos (pelo calor gerado na transdução, pelo estímulo elétrico repetitivo e por sua possível influência sobre as estruturas circunjacentes), etc.

Mais complicado ainda quando se fala de próteses de nervo óptico e cortical. A primeira seria implantada diretamente no nervo óptico, logo abaixo da inserção escleral, podendo gerar um problema técnico de grandes proporções, ao se tentar fazer conexões micrométricas com os 1,2 milhões de axônios das células ganglionares, no minúsculo diâmetro de apenas três a quatro milímetros.

A alternativa do implante cortical teria a seu favor a possibilidade de recuperação de maior número de cegos. Com ele, eliminar-se-ia todo o complexo sistema de captação e transmissão olho-nervo óptico, instalando-se o estímulo elétrico (resultante da modificação do luminoso) diretamente no cérebro. Entretanto, agora sim, como diriam os incrédulos, complica! já que aí está o maior número de conexões, sinapses e arranjos neurais do corpo humano. É verdade que, com tais próteses, já foi possível a obtenção de percepções de luz como as originadas de pressões sobre a retina (fosfenos). Mas pela complicadíssima estrutura de neurônios e suas conexões, torna-se dificílimo dispor tipograficamente os estímulos (sobre tais estruturas) de modo que a organização espacial dos pontos que lhe correspondem (forma do objeto) e suas outras características perceptuais (cores, tons e intensidades) originem uma percepção visual equivalente à da naturalmente desejada. Ademais, o implante dessa prótese no SNC pode não somente levar a danos cerebrais afetando outras funções, como a infecções causando riscos à vida.
Por isso, talvez, a proposta de transplantar células da retina, semeando-as para que restabeleçam, a seus modos, as conexões e desempenhos esperados, seduz como atalho promissor. De fato, as novas modulações do comportamento celular, viabilizadas pela terapia genética fazem prever resultados mais fisiológicos. Provavelmente, a sabedoria intrínseca dessas células guie o estabelecimento de suas sinapses e das interações neuronais de modo mais natural e efetivo, aparentando o arranjo celular da mãe natureza. Dúvida é se o segredo de genes de diferentes origens, ou de células de diferentes locais permitirão essa integração.

De todo modo merece reflexão, sobretudo, o que ocorre numa condição de perda visual aparentemente bem mais simples, a ambliopia do adulto, cuja solução ainda não foi encontrada. Nesta afecção, embora se conte com a absoluta integridade estrutural (e, supostamente, funcional) da retina, observa-se uma acentuada redução da acuidade visual, da qual se identifica a importância de novo fator para a normalidade da visão: a adequada temporalidade do desenvolvimento das competências neuronais. Depois de ultrapassado o tempo da aprendizagem visual, ou do estabelecimento apropriado de conexões sinápticas, de veiculação de sinais neurais, enfim, do funcionamento básico ao qual o sistema deve ser submetido desde cedo, extingue-se a possibilidade de boa resposta cortical (percepção visual) mesmo em presença de estímulos periféricos (retínicos ou artificiais) perfeitos. Ou seja, para perdas visuais precoces, nem sequer a estimulação perfeita seria suficiente...

Isto põe em cheque a própria estimulação, ainda que direta, do córtex visual, como enfoque para a eventual produção da visão artificial. Como já admitido, é claro que fosfenos e até imagens mais ou menos elaboradas podem ser suscitadas por estímulos diretos sobre o córtex visual. Mas, a misteriosa transformação de uma realidade objetiva em uma imagem subjetiva, para a qual concorrem conexões neuronais bem mais complicadas e numerosas, reações ainda mais específicas (como a de células que respondem a movimentos da imagem num sentido, mas não no oposto), de modo que haja correspondência unívoca entre pontos da realidade factual e os da percepção interiorizada, não parece dificuldade menor do que construir mecanismos semelhantes para as outras sensações. Ou seja, o desafio não é apenas o de criar uma visão artificial, mas uma inteligência artificial. Equivalentemente, criar um outro sistema nervoso central como o até então disponível.

Resumindo: a complexidade estrutural e funcional do sistema visual é de tal ordem, que não se pode ter a pretensão de reproduzí-la satisfatoriamente, pelo menos não no momento presente da evolução tecnológica. Pode-se dar como analogia a concepção de que a visão seja uma intricada trama musical, harmoniosa e melódica, resultante de um instrumento de difícil operacionalização (o cérebro) mas tocado por um competente arranjador (o olho). Quando a ciência puder entender todas as pautas e, mais, interpretá-las com a habilidade do artista original, ele então poderá ser dispensado, ou artificialmente substi- 
tuído. Mas ainda é cedo para tal pretensão. Não se trata de derrotismo ou de falta de fé no potencial da ciência, que se desdobra continuamente em conquistas sempre surpreendentes e escarnece daqueles que dela desdenham. Ao contrário, reconhece-se que a maravilha da ciência se fundamente precisamente em sua teimosia, na esperança implícita de que pode conseguir, na fé inabalável em sua aparentemente infinita capacidade de renovação e de superação, herança natural da humanidade e seu orgulho. E acredita-se, prudentemente, que, apesar de tudo e das dificuldades (que são mais da Biologia e de suas intrincadas funções do que da Física e de suas alternativas) o Homem chegue lá.
Trata-se, entretanto, de uma medida de sensatez que recomenda que, entrementes, se conserve o músico e se preservem suas condições de aprendizagem natural. Que se cuide bem dele, insubstituível que ainda é, prevenindo suas doenças e melhorando os procedimentos que lhe corrijam os defeitos de sua atuação. Que se lhe garantam, desde a infância, as condições necessárias a seu bom desenvolvimento. Fica bem mais barato e a música sai mais linda.

E se toda essa preocupação é válida para a visão, quanto mais não seria necessário para preservar a dignidade de seus usuários ou daqueles que não a possuem, o Homem em sua inteireza total?

\title{
$6^{\circ}$ Congresso de Oftalmologia do Triângulo Mineiro
}

\author{
07 à 09 de Novembro de 2002 \\ Pavilhão \\ de \\ Eventos da
do Triângulo \\ Faculdade \\ de \\ Mineiro \\ UBERABA \\ $M G$ \\ Promoção: Sociedade de Oftalmologia do Triângulo Mineiro
}

INFORMAÇÕES: tel.: (34) 3338-5343

fax.: (34) 3312-0657

E-mail: diretoria.pa@terra.com.br 